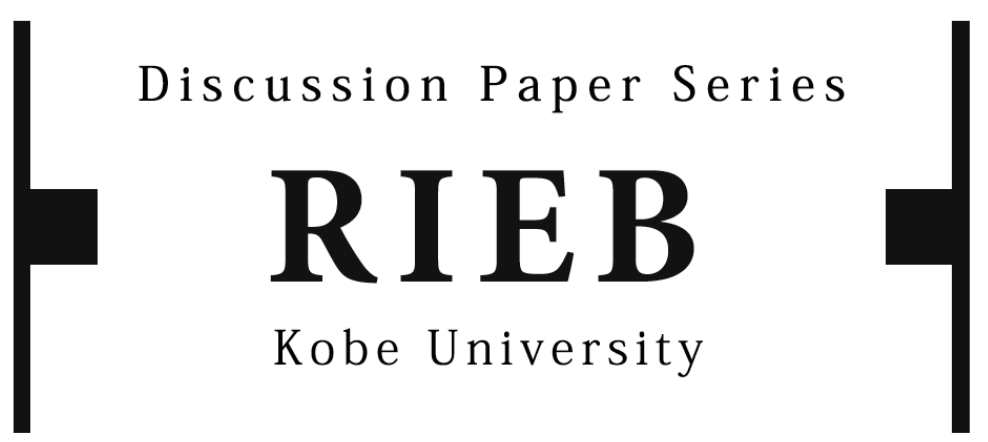

DP2011-27

Threats or Promises?

A Built-in Mechanism of Gradual Reciprocal Trade Liberalization

Taiji FURUSAWA

Takashi KAMIHIGASHI

Revised January 13, 2012

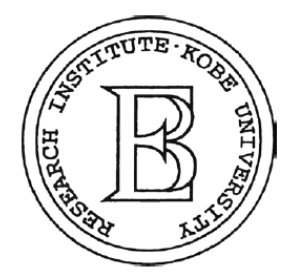

Research Institute for Economics and Business Administration

Kobe University

2-1 Rokkodai, Nada, Kobe 657-8501 JAPAN 


\title{
Threats or Promises? A Built-in Mechanism of Gradual Reciprocal Trade Liberalization*
}

\author{
Taiji Furusawa $^{\dagger}$ and Takashi Kamihigashi ${ }^{\ddagger}$
}

January 13, 2012

\begin{abstract}
We analyze an infinitely repeated tariff-setting game played by two large countries with alternating moves. We focus on the subgame perfect equilibria in which each country chooses its tariff according to a stationary function of the other country's tariff. We show that there are many equilibria with two steady states, one with higher tariffs (but still lower than the static Nash tariffs), the other with lower tariffs. We also show that there is a special class of equilibria in which there exists a unique, globally stable steady state. In both types of equilibria, one country unilaterally reduces its tariff from the static Nash equilibrium, the other country reciprocates in response to the first country's implicit "promise" to lower its tariff even further, and this process continues forever, converging to a steady state with tariffs lower than the static Nash tariffs. Therefore, promises, rather than threats, induce countries to gradually reduce their tariffs.

JEL Classification numbers: C73, F13
\end{abstract}

*Furusawa gratefully acknowledges financial supports from the Seimeikai Foundation, the Japan Society for Promotion of Science Research, and the Ministry of Education, Culture, Sports, Science and Technology of Japan (the 21st Century COE and Global COE). Part of the analysis was conducted when Furusawa was an associate of the Program on U.S.-Japan Relations at Harvard University. Furusawa gratefully acknowledges their hospitality and financial support from the Abe Fellowship. We are grateful to Eric Bond, Pierre-Philippe Combes, Michael Conlin, Jonathan Eaton, Joseph Greenberg, Toshihiro Ichida, Makoto Ikema, Yoshimasa Komoriya, Hideo Konishi, Rodney Ludema, Yoshihiro Mizoguchi, Dilip Mookherjee, Yuriy Tchamourliyski, Vitor Trindade, seminar participants at Boston College, Boston University, City University of Hong Kong, Hitotsubashi University, Kobe University, McGill University, Otaru University of Commerce, Syracuse University, and University of Sydney, and participants of Midwest International Trade Meeting (spring 2002) and European Trade Study Group Fifth Annual Conference for helpful discussions and comments. We are also grateful to two anonymous referees for their helpful comments.

${ }^{\dagger}$ Graduate School of Economics, Hitotsubashi University, 2-1 Naka, Kunitachi, Tokyo 186-8601 JAPAN. Email: furusawa@econ.hit-u.ac.jp. Tel/Fax: +81-42-580-8866.

${ }^{\ddagger}$ RIEB, Kobe University, Rokkodai, Nada, Kobe 657-8501 JAPAN. Email: tkamihig@rieb.kobe-u.ac.jp. 


\section{Introduction}

Why does a country sometimes liberalize trade unilaterally? Trade theory suggests that trade liberalization benefits a country as long as it is small. But why do even large countries sometimes liberalize trade unilaterally? A notable example is Britain's unilateral trade liberalization in the 1840s, including the repeal of the Corn Laws in 1846 (Conybeare, 2002). Did Britain act unilaterally because it believed that unilateral trade liberalization itself would benefit Britain? Or did Britain hope that other countries would follow suit? Bhagwati (2002) argues that the latter idea occurred to British Prime Minister Sir Robert Peel, who showed leadership in abolishing the Corn Laws. Indeed, most European countries gradually liberalized trade from the 1840s to the 1880s, following the continual free trade movement by Britain (Bairoch, 1989; Kindleberger, 1975; Conybeare, 2002, p. 47). History witnessed what is now known as gradual trade liberalization.

In the literature on trade liberalization, threats play an important role in sustaining liberalized trade. In the framework of a repeated tariff-setting game, Dixit (1987) shows that liberalized trade can be sustained by the threat of reverting forever to the static Nash equilibrium after any deviation. The threat of Nash reversion is also used to support an entire process of trade liberalization by Staiger (1995a), Furusawa and Lai (1999), and Bond and Park (2002). They all consider trade agreements between two countries in which the countries gradually decrease their tariffs while at all times satisfying an incentive constraint such that any deviation triggers Nash reversion. These studies show that optimal reciprocal liberalization must be gradual if skills of workers who are displaced from the import-competing industry dissipate (Staiger, 1995a), if there are sectoral adjustment costs (Furusawa and Lai, 1999), or if the incentive constraint is binding for only one of the countries because of size asymmetry (Bond and Park, 2002). ${ }^{1}$

\footnotetext{
${ }^{1}$ Krishna and Mitra (1999) and Coates and Ludema (2001) explain unilateral trade liberalization based on lobbying activities, but they do not consider the gradual feature of liberalization processes. Baldwin (2010) introduces some political economy mechanisms of unilateral trade liberalization by developing nations with particular emphasis on the role of production unbundling.
} 
However, since punitive retaliatory actions are seldom observed in reality, the analysis using the threat of reverting to the static Nash equilibrium may not be realistic. Furthermore, such threats are effective only in sustaining an already established (or agreed-upon) process of trade liberalization. Once any deviation occurs, the cooperative process can never be restored.

In this paper, we argue that when a country liberalizes trade unilaterally, what motivates other countries to follow suit is its implicit promise to liberalize trade further if they reciprocate. For this purpose we study a simple tariff-setting game with alternating moves between two large countries. Each country's one-shot payoff is simply the sum of import and export surplus, and the countries take turns in setting their tariffs: in the first period one country chooses its tariff, in the second period the other country chooses its tariff, in the third period the first country chooses its tariff again, and so on. By looking at an alternating-move game, we can capture a realistic feature of the information structure, that when countries choose their trade policies they can observe other countries' concurrent trade policies. Maskin and Tirole (1988) suggest another rationale for alternating-move games: that they are effectively the same as games with endogenous timing of players' moves, which suits the analysis of countries' tariff-setting behavior. In this framework, we focus on the subgame perfect equilibria in which each country, on its turn to move, chooses its tariff according to a stationary function of the other country's current tariff. A subgame perfect equilibrium in this class is termed an "immediately reactive equilibrium" (IRE) by Kamihigashi and Furusawa (2010), and this class seems particularly suitable for capturing the sequential and reciprocal aspects of trade liberalization.

We show that there are many IREs that have two steady states, one with higher tariffs, the other with lower tariffs; the higher-tariff steady state is locally stable, and the lower-tariff steady state is stable from below but unstable from above. Then, we look at an IRE that satisfies a certain criterion of efficiency. Unlike other IREs, in this "effectively efficient" IRE 
(defined in Section 3), there is a unique, globally stable steady state.

In many of these equilibria, including all the effectively efficient IREs, if the initial tariff vector is at the static Nash equilibrium, the countries gradually decrease their tariffs toward a steady state with low tariffs. More specifically, the country that is allowed to move in the first period cuts its tariff, the second country responds by cutting its tariff, the first country then reacts by further cutting its tariff again, and this process continues and gradually converges to the steady state. Hence these equilibria induce gradual trade liberalization initiated by unilateral tariff reduction. Furthermore, when the first country cuts its tariff in the first period, the second country is not threatened to reciprocate. If it did not reciprocate, the first country would simply keep its tariff unchanged. It is therefore the first country's implicit promise to lower its tariff even further when the second country reciprocates that motivates the second country to lower its tariff.

A steady state of an IRE has the property that it is supported by a minimum threat: each country simply makes the other country indifferent between raising its tariff and staying at the steady state. Even after a deviation, each country promises to lower its tariff as long as the other country follows suit, which makes it possible to restore the steady state in a self-enforcing way. Therefore, any stable steady state of an IRE has a built-in mechanism to restore itself after a deviation. This is in sharp contrast with the aforementioned studies on gradual trade liberalization, which use the threat of Nash reversion to support a cooperative process that could be lost forever in case of any deviation.

We should mention that Johnson (1953-54) studies a similar framework in which two large countries alternately select their tariffs. In his model, each country chooses its tariff in a myopic way in response to the tariff chosen by the other country in the previous period. The tariff vector then converges either to the static Nash equilibrium or to a cycle around the Nash equilibrium. By contrast, in our model countries are fully rational and there are many equilibria in which the tariff vector converges to a steady state with tariffs lower than 
at the static Nash equilibrium.

The rest of the paper is organized as follows. In Section 2 we describe our tariff-setting game and formally define IREs. In Section 3 we establish some general properties of the IREs of our model based on Kamihigashi and Furusawa's (2010) results. In Section 4 we describe various IREs of interest and discuss trade liberalization processes. In Section 5 we offer some concluding remarks.

\section{The Model}

We consider an alternating-move, tariff-setting game between two large countries, 1 and 2. Each country $i$ consumes three goods, country $i$ 's export good, country $j$ 's $(j \neq i)$ export good, and a common numeraire good; the representative consumer's utility function is additively separable in the three goods and linear in the numeraire good. Social welfare of each country can thus be represented by the total surplus derived from the markets of the non-numeraire goods and can thus be measured by gains from trade. ${ }^{2}$

We can compute gains from trade from each country's import demand and export supply functions. Country $i$ imposes a tariff at a specific rate of $\tau_{i} \geq 0$ on imports from country $j \neq i$. Country $i$ 's import demand is assumed to be a strictly decreasing, continuous function of the price of imports such that it is equal to zero at country $i$ 's autarkic equilibrium price, whereas its export supply is a strictly increasing, continuous function of the price of exports. Country $i$ 's import surplus $m_{i}\left(\tau_{i}\right)$ is the area below the import demand curve and above the world price level. Country $i$ 's export surplus $x_{i}\left(\tau_{j}\right)$ is the area below the world price level and above the export supply curve. The one-shot payoff of country $i$ is its gains from trade,

\footnotetext{
${ }^{2}$ Two non-numeraire goods may be a capital-intensive manufacture good, such as automobiles, and a labor-intensive good, such as clothing. A non-numeraire good may be agricultural goods. Strictly speaking, it is not surprising that a tariff on automobiles affects to some degree the demand for clothing and agricultural products through substitution and income effects. Since the direction and degree of these effects are generally ambiguous, however, it is not uncommon to assume that consumers' utility functions are additively separable. See, for example, Staiger (1995a,b) and Furusawa and Lai (1999).
} 
i.e., the sum of its import surplus $m_{i}\left(\tau_{i}\right)$ and export surplus $x_{i}\left(\tau_{j}\right)$ :

$$
u_{i}\left(\tau_{i}, \tau_{j}\right)=m_{i}\left(\tau_{i}\right)+x_{i}\left(\tau_{j}\right)
$$

Optimal tariff theory suggests that $m_{i}\left(\tau_{i}\right)$ is increasing where $\tau_{i}$ is small and decreasing where $\tau_{i}$ is large. We assume for simplicity that $m_{i}\left(\tau_{i}\right)$ has a single peak at $\tau_{i}^{N}>0$ and is strictly increasing for $\tau_{i}<\tau_{i}^{N}$. The export-surplus function $x_{i}$ is a strictly decreasing continuous function of $\tau_{j}$. In Appendix $\mathrm{A}$ we derive the surplus functions $m_{i}$ and $x_{i}$ explicitly in a parametric example based on linear demand and supply functions.

Since $\tau_{i}^{N}$ is country $i$ 's strictly dominant strategy in the one-shot game, $\left(\tau_{1}^{N}, \tau_{2}^{N}\right)$ is a unique static Nash equilibrium. We henceforth restrict the feasible set of country $i$ 's tariffs to $\left[0, \tau_{i}^{N}\right]$, as we are mainly interested in tariff reduction processes. A more general case allowing for $\tau_{i}>\tau_{i}^{N}$ can be analyzed with Kamihigashi and Furusawa's (2010) results.

Let $T_{1}=\{1,3,5, \cdots\}$ and $T_{2}=\{2,4,6, \cdots\}$ denote the sets of periods in which country 1 and country 2 select their individual tariffs, respectively. We focus on the subgame perfect equilibria in which country $i$, in its turn to move (i.e., $t \in T_{i}$ ), selects its tariff $\tau_{i, t}$ according to a stationary reaction function $f_{i}$ of country $j$ 's current tariff $\tau_{j, t}$, which was selected in the previous period. Such equilibria are termed immediately reactive equilibria (IREs) by Kamihigashi and Furusawa (2010). Since country $i$ cannot change its tariff from $\tau_{i, t}$ in period $t+1 \in T_{j}$, we have $\tau_{i, t+1}=\tau_{i, t}$ for all $t \in T_{i}$. Let $\delta_{i} \in(0,1)$ denote country $i$ 's discount factor. Then, given country $j$ 's reaction function $f_{j}$, country $i$ maximizes the discounted sum of one-shot payoffs from period $i(=1$ or 2$)$ onward:

$$
\begin{array}{cl}
\max _{\left\{\tau_{i, t}\right\}_{t \in T_{i}}} & \sum_{t=i}^{\infty} \delta_{i}^{t-i}\left[m_{i}\left(\tau_{i, t}\right)+x_{i}\left(\tau_{j, t}\right)\right] \\
\text { s.t. } & \tau_{i, t+1}=\tau_{i, t} \quad \text { for } t \in T_{i}, \\
& \tau_{j, t+1}=\tau_{j, t}=f_{j}\left(\tau_{i, t}\right) \quad \text { for } t \in T_{j}, \\
& \tau_{j, i} \text { given. }
\end{array}
$$

We say that country $i$ 's reaction function $f_{i}$ is a best response to country $j$ 's reaction 
function $f_{j}$ if for any $\tau_{j, i} \in\left[0, \tau_{j}^{N}\right]$, the above maximization problem has a solution $\left\{\tau_{i, t}\right\}_{t=i}^{\infty}$ such that $\tau_{i, t}=f_{i}\left(\tau_{j, t}\right)$ for all $t \in T_{i}$. We call a pair of reaction functions $\left(f_{1}, f_{2}\right)$ an immediately reactive equilibrium (IRE) if $f_{1}$ is a best response to $f_{2}$, and vice versa. ${ }^{3}$

Given an $\operatorname{IRE}\left(f_{1}, f_{2}\right)$, we say that $\left(\tau_{1}, \tau_{2}\right) \in\left[0, \tau_{1}^{N}\right] \times\left[0, \tau_{2}^{N}\right]$ is a steady state if $\tau_{1}=f_{1}\left(\tau_{2}\right)$ and $\tau_{2}=f_{2}\left(\tau_{1}\right)$. Needless to say, if the game starts from a steady state $\left(\tau_{1}, \tau_{2}\right)$, each country $i$ keeps choosing $\tau_{i}$ forever according to $f_{i}$.

\section{General Properties of IREs}

In this section we present some useful properties of IREs. Since the tariff-setting game in this paper is a special case of the general model studied by Kamihigashi and Furusawa (2010), the results obtained by Kamihigashi and Furusawa (2010) apply here. However, many of those results are considerably simplified (and easier to understand) because of the extra assumption that $m_{i}$ is strictly increasing (together with the assumption that $x_{i}$ is strictly decreasing). This assumption also enables us to establish some additional results.

In this section we assume only that $m_{i}$ is strictly increasing and continuous in $\tau_{i}$, and that $x_{i}$ is strictly decreasing and continuous in $\tau_{j}$. Additional assumptions will be introduced in the next section.

Let us define the function $w_{i}:\left[0, \tau_{i}^{N}\right] \times\left[0, \tau_{j}^{N}\right] \rightarrow \mathbb{R}$ by

$$
w_{i}\left(\tau_{i}, \tau_{j}\right)=m_{i}\left(\tau_{i}\right)+\delta_{i} x_{i}\left(\tau_{j}\right)
$$

We call this function country $i$ 's effective payoff since country $i$ in effect seeks to maximize the discounted sum of effective payoffs. Indeed, country $i$ 's discounted sum of payoffs from

\footnotetext{
${ }^{3}$ The concept of IRE is similar to that of Markov perfect equilibrium (Maskin and Tirole, 1988, 2001) in that both IRE and Markov perfect equilibrium are the subgame perfect equilibrium in which strategies depend only on the history that affects the continuation payoff. IRE is distinct from Markov perfect equilibrium, however, if this "payoff relevant history" is restricted for Markov perfect equilibrium such that a Markov strategy is measurable with respect to the coarsest partition of histories for which, if all other players use measurable strategies, each player's decision-problem is also measurable (Maskin and Tirole, 2001). According to this definition of Markov strategies, different payoff relevant histories should affect players' behavior differently for Markov perfect equilibrium, whereas this restriction is absent for IRE.
} 
period $i$ onward is written as

$$
\begin{aligned}
& \sum_{t=i}^{\infty} \delta_{i}^{t-i}\left[x_{i}\left(\tau_{j, t}\right)+m_{i}\left(\tau_{i, t}\right)\right] \\
& =x_{i}\left(\tau_{j, i}\right)+\sum_{t=1}^{\infty} \delta_{i}^{t-1}\left[m_{i}\left(\tau_{i, t}\right)+\delta_{i} x_{i}\left(\tau_{j, t+1}\right)\right] \\
& =x_{i}\left(\tau_{j, i}\right)+\sum_{t=1}^{\infty} \delta_{i}^{t-1} w_{i}\left(\tau_{i, t}, \tau_{j, t+1}\right)
\end{aligned}
$$

Since country $i$ has no influence on $\tau_{j, i}$, its problem is equivalent to maximizing the discounted sum of effective payoffs. It then follows from (3.2) that each country $i$ effectively solves the static problem of maximizing $w_{i}\left(\tau_{i}, f_{j}\left(\tau_{i}\right)\right)$ taking $f_{j}$ as given.

To characterize country $i$ 's reaction function, let $w_{i}^{*}\left(f_{j}\right)$ denote country $i$ 's maximum feasible effective payoff (provided that it exists):

$$
w_{i}^{*}\left(f_{j}\right) \equiv \max _{\tau_{i} \in\left[0, \tau_{i}^{N}\right]} w_{i}\left(\tau_{i}, f_{j}\left(\tau_{i}\right)\right)
$$

Note that the maximization problem that country $i$ faces in (3.3) does not involve $\tau_{j}$. This implies that if $f_{i}$ is a best response to $f_{j}$, then for any $\tau_{j}$, choosing $\tau_{i}=f_{i}\left(\tau_{j}\right)$ gives country $i$ its maximum feasible effective payoff $w_{i}^{*}\left(f_{j}\right)$. Thus, we have the following lemma (see Kamihigashi and Furusawa 2010, Lemma 2.1, for a formal proof).

Lemma 3.1. Country i's reaction function $f_{i}$ is a best response to country j's reaction function $f_{j}$ if and only if

$$
w_{i}\left(f_{i}\left(\tau_{j}\right), f_{j}\left(f_{i}\left(\tau_{j}\right)\right)\right)=w_{i}^{*}\left(f_{j}\right) \quad \text { for any } \tau_{j} \in\left[0, \tau_{j}^{N}\right]
$$

In other words, $\left(f_{1}, f_{2}\right)$ is an IRE if and only if (3.4) holds for $i=1,2$.

Lemma 3.1 implies that for a given $\tau_{j}$, choosing $\tau_{i}=f_{i}\left(\tau_{j}\right)$ will bring the next period's tariff vector on the level curve of country $i$ 's effective payoff at the value of $w_{i}^{*}\left(f_{j}\right)$, which we call country $i$ 's optimal level curve (in response to $f_{j}$ ). To represent level curves of country $i$ 's effective payoff, let us define a function $g_{j}^{\omega_{i}}$ of $\tau_{i}$ by

$$
\omega_{i}=w_{i}\left(\tau_{i}, g_{j}^{\omega_{i}}\left(\tau_{i}\right)\right)
$$




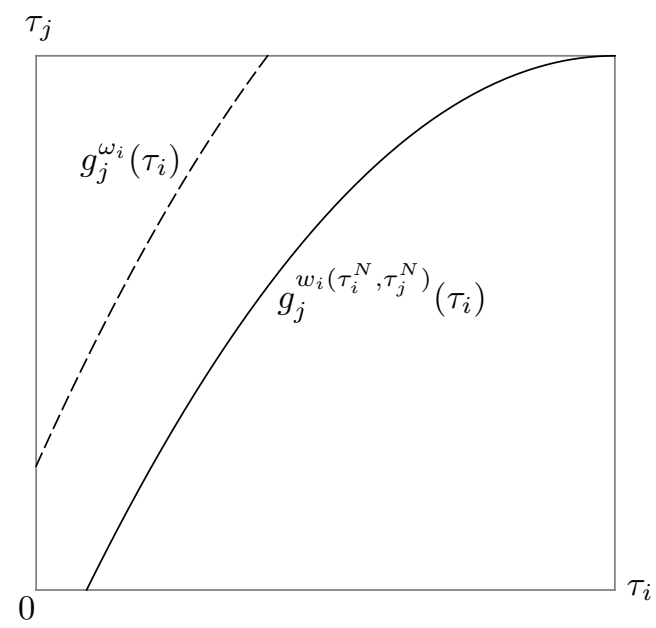

Figure 1: Level curves $g_{j}^{w_{i}\left(\tau_{i}^{N}, \tau_{j}^{N}\right)}$ and $g_{j}^{\omega_{i}}$ with $\omega_{i}<w_{i}\left(\tau_{i}^{N}, \tau_{j}^{N}\right)$

Put differently, the graph of $g_{j}^{\omega_{i}}$ is the level curve of country $i$ 's effective payoff at the value of $\omega_{i}$, which we also call the level curve $g_{j}^{\omega_{i}}$ to simplify the exposition. Figure 1 shows two such graphs that correspond to $\omega_{i}=w_{i}\left(\tau_{i}^{N}, \tau_{j}^{N}\right)$ and $\omega_{i}<w_{i}\left(\tau_{i}^{N}, \tau_{j}^{N}\right)$. ${ }^{4}$ Since $m_{i}$ is strictly increasing in $\tau_{i}$ and $x_{i}$ is strictly decreasing in $\tau_{j}, g_{j}^{\omega_{i}}$ is a strictly increasing function of $\tau_{i}$. The lower the level curve, the higher the effective payoff for country $i$.

Now, we can restate Lemma 3.1 in terms of level curves as follows.

Lemma 3.2. A pair of reaction functions $\left(f_{1}, f_{2}\right)$ is an IRE if and only if for $i=1,2$,

$$
f_{j}\left(f_{i}\left(\tau_{j}\right)\right)=g_{j}^{w_{i}^{*}\left(f_{j}\right)}\left(f_{i}\left(\tau_{j}\right)\right) \quad \text { for any } \tau_{j} \in\left[0, \tau_{j}^{N}\right]
$$

Again, this lemma shows that $\left(f_{1}, f_{2}\right)$ is an IRE if and only if for $i=1,2$, choosing $\tau_{i}=$ $f_{i}\left(\tau_{j}\right)$ induces country $j$ to choose $\tau_{j}=f_{j}\left(f_{i}\left(\tau_{j}\right)\right)$ such that the tariff vector $\left(f_{i}\left(\tau_{j}\right), f_{j}\left(f_{i}\left(\tau_{j}\right)\right)\right)$ is on country $i$ 's optimal level curve. Thus, we have the following lemma.

Lemma 3.3. If $\left(f_{1}, f_{2}\right)$ is an IRE, then for $i=1,2$,

$$
w_{i}^{*}\left(f_{j}\right) \geq w_{i}\left(\tau_{i}^{N}, \tau_{j}^{N}\right)
$$

\footnotetext{
${ }^{4}$ As Figure 1 shows, the domain of $g_{j}^{\omega_{i}}$ may not cover the entire feasible set of $\tau_{i}$ so that it must be appropriately restricted if necessary.
} 


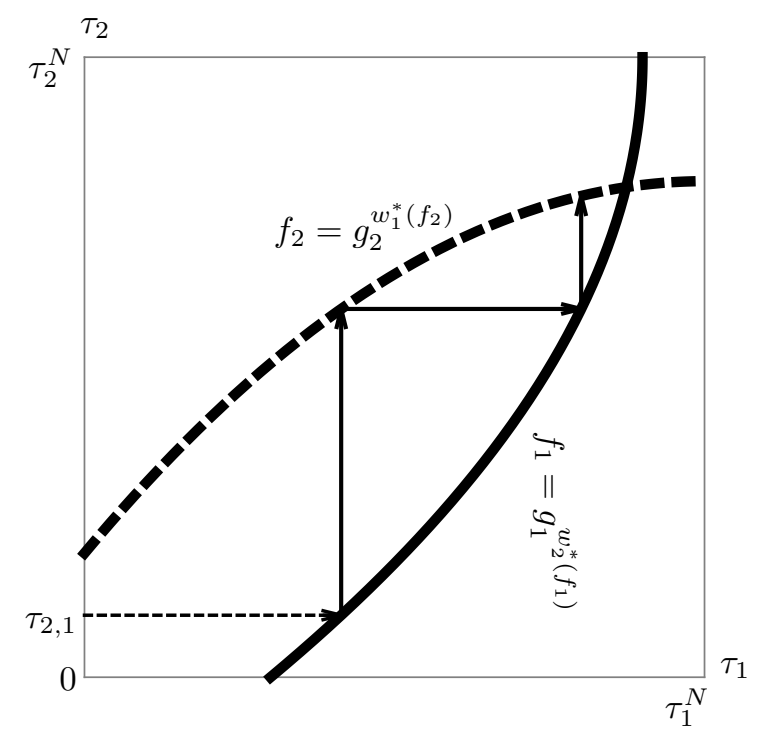

Figure 2: IRE with $f_{i}=g_{i}^{w_{j}^{*}\left(f_{i}\right)}$ for $i=1,2$

Suppose to the contrary that $w_{i}^{*}\left(f_{j}\right)<w_{i}\left(\tau_{i}^{N}, \tau_{j}^{N}\right)$ so that country $i$ 's optimal level curve is above the graph of $g_{j}^{w_{i}\left(\tau_{i}^{N}, \tau_{j}^{N}\right)}$, e.g., the dotted level curve in Figure 1. Then, country $i$ can obtain $w_{i}\left(\tau_{i}^{N}, f_{j}\left(\tau_{i}^{N}\right)\right) \geq w_{i}\left(\tau_{i}^{N}, \tau_{j}^{N}\right)>w_{i}^{*}\left(f_{j}\right)$ for any $f_{j}$ by choosing $\tau_{i}^{N}$, which is in contradiction with the definition of $w_{i}^{*}{ }^{5}$ Thus, country $i$ 's effective payoff in an IRE must be no less than its minimax effective payoff.

Figure 2 illustrates Lemma 3.2 and Lemma 3.3 by presenting an IRE such that $f_{i}=g_{i}^{w_{j}^{*}\left(f_{i}\right)}$ for $i=1,2$. The figure also depicts an IRE path $\left\{\left(\tau_{1, t}, \tau_{2, t}\right)\right\}_{t=1}^{\infty}$ induced by $\left(f_{1}, f_{2}\right)$. In this example, country $i$ 's reaction function $f_{i}$ is nothing but the function that characterizes country $j$ 's optimal level curve. Given a $\tau_{2,1}$, country 1 chooses $\tau_{1,1}=f_{1}\left(\tau_{2,1}\right)$ in period 1 so that the tariff vector $\left(f_{1}\left(\tau_{2,1}\right), f_{2}\left(f_{1}\left(\tau_{2,1}\right)\right)\right)$ that prevails in period 2 is on country 1's optimal level curve (illustrated by the dotted curve), as Lemma 3.2 indicates. In period 2, country 2 chooses $\tau_{2,2}=f_{2}\left(f_{1}\left(\tau_{2,1}\right)\right)$ so that $\left(f_{2}\left(f_{1}\left(\tau_{2,1}\right)\right), f_{1}\left(f_{2}\left(f_{1}\left(\tau_{2,1}\right)\right)\right)\right)$ that prevails in period 3 is on country 2's optimal level curve (illustrated by the solid curve). The IRE path converges to the intersection of the two optimal level curves.

We can infer from this example an important property of IRE paths.

\footnotetext{
${ }^{5}$ It follows from $\tau_{j} \in\left[0, \tau_{j}^{N}\right]$ that $f_{j}\left(\tau_{i}^{N}\right) \leq \tau_{j}^{N}$, which gives us the first inequality.
} 
Lemma 3.4. Given an IRE $\left(f_{1}, f_{2}\right)$, let $\left\{\left(\tau_{1, t}, \tau_{2, t}\right)\right\}_{t=1}^{\infty}$ be any IRE path. For any $t \geq 2$, $\left(\tau_{1, t}, \tau_{2, t}\right)$ is on country 1 's optimal level curve, i.e., $\tau_{2, t}=g_{2}^{w_{1}^{*}\left(f_{2}\right)}\left(\tau_{1, t}\right)$, if $t \in T_{2}$, while $\left(\tau_{1, t}, \tau_{2, t}\right)$ is on country 2's optimal level curve, i.e., $\tau_{1, t}=g_{1}^{w_{2}^{*}\left(f_{1}\right)}\left(\tau_{2, t}\right)$, if $t \in T_{1}$.

See Kamihigashi and Furusawa (2010, Theorem 4.1) for the proof.

This result shows that any IRE path is characterized by the corresponding level curves $\left(g_{1}^{w_{2}^{*}\left(f_{1}\right)}, g_{2}^{w_{1}^{*}\left(f_{2}\right)}\right)$ except for the tariff chosen in the initial period. The initial period must be excluded because $\tau_{2,1}$ is an arbitrary initial condition that need not be optimal for country 2 given country 1's reaction function $f_{1}$. In Figure 2, by contrast, any IRE path stays on the optimal level curves for all $t \geq 1$, which is also consistent with Lemma 3.4.

Lemma 3.4 implies that any steady state must be on both countries' optimal level curves. We state this result as a corollary.

Corollary 3.1. Any steady state of an $\operatorname{IRE}\left(f_{1}, f_{2}\right)$ is an intersection of the two corresponding level curves, the graphs of $g_{2}^{w_{1}^{*}\left(f_{2}\right)}$ and $g_{1}^{w_{2}^{*}\left(f_{1}\right)}$.

We say that a pair of level curves $\left(g_{1}^{\omega_{2}}, g_{2}^{\omega_{1}}\right)$ is supported by an IRE if there exists an $\operatorname{IRE}\left(f_{1}, f_{2}\right)$ such that $\omega_{i}=w_{i}^{*}\left(f_{j}\right)$ for both $i$. Given a pair of level curves $\left(g_{1}^{\omega_{2}}, g_{2}^{\omega_{1}}\right)$, let $\left(\underline{\tau}_{1}^{\omega_{1}, \omega_{2}}, \underline{\tau}_{2}^{\omega_{2}, \omega_{1}}\right)$ denote the lower left corner of the set

$$
\left\{\left(\tau_{1}, \tau_{2}\right) \in\left[0, \tau_{1}^{N}\right] \times\left[0, \tau_{2}^{N}\right]: \tau_{2} \leq g_{2}^{\omega_{1}}\left(\tau_{1}\right), \tau_{1} \leq g_{1}^{\omega_{2}}\left(\tau_{2}\right)\right\}
$$

which is the shaded area in each panel of Figure 3 when $\omega_{i}=w_{i}\left(\tau_{i}^{N}, \tau_{j}^{N}\right)$ for $i=1,2$. Each of these shaded areas also represents the set of all steady states supported by IREs, as Appendix B shows.

The following result characterizes all the pairs of level curves supported by IREs.

Lemma 3.5. A pair of level curves $\left(g_{1}^{\omega_{2}}, g_{2}^{\omega_{1}}\right)$ is supported by an IRE if and only if (i) the graphs of $g_{1}^{\omega_{2}}$ and $g_{2}^{\omega_{1}}$ have an intersection in $\left[0, \tau_{1}^{N}\right] \times\left[0, \tau_{2}^{N}\right]$ and (ii) $\omega_{i} \geq w_{i}\left(\tau_{i}^{N}, \tau_{j}^{N}\right)$ for $i=1,2$. 


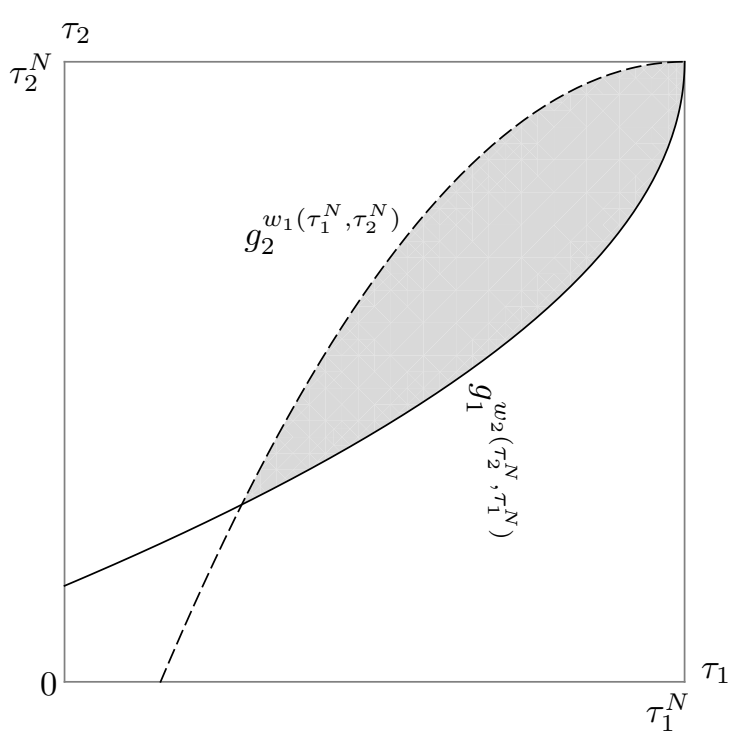

(a)

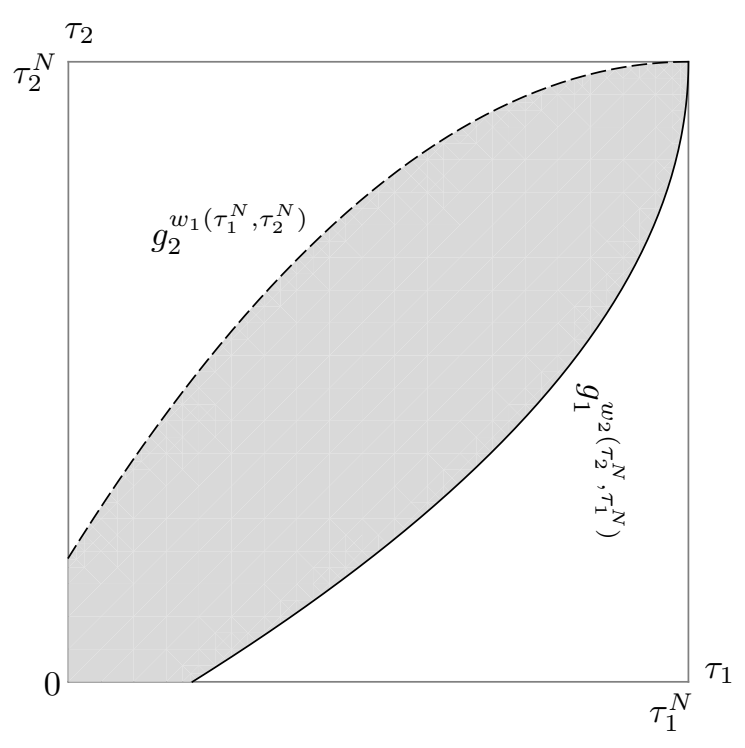

(b)

Figure 3: Set of all steady states supported by IREs

This result follows from Kamihigashi and Furusawa (2010, Theorem 5.1). Condition (i) is necessary because if it is violated, there is no path that stays on the level curves forever, which contradicts Lemma 3.4, as Figure 4 shows. Condition (ii) is a requirement from Lemma 3.3.

Now, we are ready to state the proposition that characterizes an important class of IREs.

Proposition 3.1. Let $\left(g_{1}^{\omega_{2}}, g_{2}^{\omega_{1}}\right)$ satisfy the two conditions (i) and (ii) in Lemma 3.5. Then, the pair of reaction functions $\left(f_{1}, f_{2}\right)$ defined below is an IRE:

$$
f_{i}\left(\tau_{j}\right)=\max \left\{g_{i}^{\omega_{j}}\left(\tau_{j}\right), \underline{\tau}_{i}^{\omega_{i}, \omega_{j}}\right\} \quad \text { for } i=1,2
$$

We say that an IRE satisfying (3.5) is regular. Figure 5 illustrates a typical regular IRE; the IRE depicted in Figure 2 is also regular. It is readily verified that in either IRE, depicted in Figure 2 or Figure 5, the IRE path starting with any $\tau_{2,1} \in\left[0, \tau_{2}^{N}\right]$ satisfies Lemma 3.4.

The regular IRE is indeed the simplest IRE given the result described in the following lemma. 


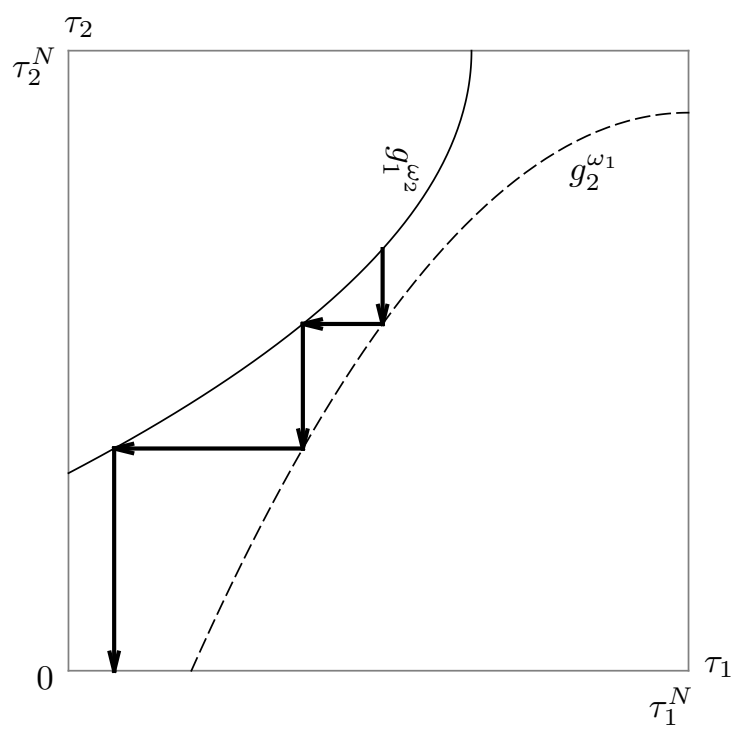

Figure 4: Level curves not supported by IRE

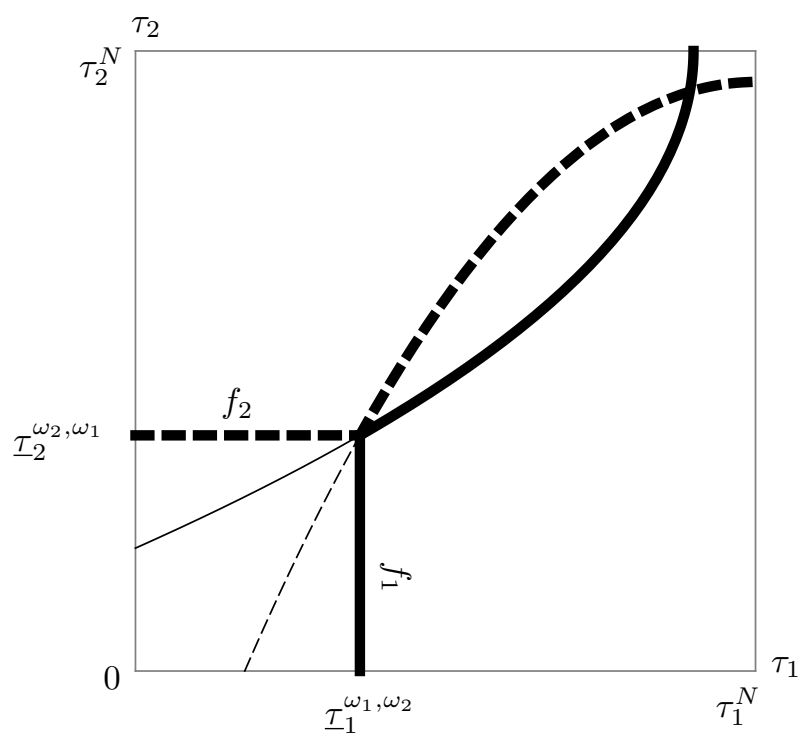

Figure 5: Regular IRE 
Lemma 3.6. For any $\operatorname{IRE}\left(f_{1}, f_{2}\right)$, we have $f_{i}\left(\tau_{j}\right) \geq \underline{\tau}_{i}^{\omega_{i}, \omega_{j}}$ for any $\tau_{j} \in\left[0, \tau_{j}^{N}\right]$ and $i=1,2$.

To see why it must be the case that $f_{i}\left(\tau_{j}\right) \geq \underline{\tau}_{i}^{\omega_{i}, \omega_{j}}$, let us suppose to the contrary that $f_{1}\left(\tau_{2}^{\prime}\right)<\underline{\tau}_{1}^{\omega_{1}, \omega_{2}}$ at some $\tau_{2}^{\prime} \in\left[0, \tau_{2}^{N}\right]$. Then, if $\tau_{2,1}=\tau_{2}^{\prime}$, we have $\tau_{1,1}=f_{1}\left(\tau_{2}^{\prime}\right)<$ $\underline{\tau}_{1}^{\omega_{1}, \omega_{2}}$, which implies from Lemma 3.4 that $\left(\tau_{1,2}, \tau_{2,2}\right)$ is on country 1 's optimal level curve in $\left[0, \underline{\tau}_{1}^{\omega_{1}, \omega_{2}}\right] \times\left[0, \underline{\tau}_{2}^{\omega_{2}, \omega_{1}}\right]$ (see Figure 5). Lemma 3.4 further implies that the subsequent path would follow as indicated in Figure 4, eventually violating Lemma 3.4. Thus, $f_{i}\left(\tau_{j}\right) \geq \underline{\tau}_{i}^{\omega_{i}, \omega_{j}}$ for any $\tau_{j} \in\left[0, \tau_{j}^{N}\right]$. See Kamihigashi and Furusawa (2010, Proposition 5.1) for a formal proof.

For the rest of the paper, we focus on regular IREs, which are guaranteed to exist whenever an IRE exists. We are especially interested in a regular IRE that satisfies a certain criterion of efficiency.

We say that an $\operatorname{IRE}\left(f_{1}, f_{2}\right)$ is effectively efficient if there is no $\operatorname{IRE}\left(\tilde{f}_{1}, \tilde{f}_{2}\right)$ such that $w_{1}^{*}\left(f_{2}\right) \leq w_{1}^{*}\left(\tilde{f}_{2}\right)$ and $w_{2}^{*}\left(f_{1}\right) \leq w_{2}^{*}\left(\tilde{f}_{2}\right)$ with at least one of the inequalities holding strictly. In other words, an effectively efficient IRE is not Pareto dominated by any other IRE in terms of effective payoffs. Effective efficiency can also be characterized graphically:

Lemma 3.7. An IRE $\left(f_{1}, f_{2}\right)$ is effectively efficient if and only if the graphs of $g_{2}^{w_{1}^{*}\left(f_{2}\right)}$ and $g_{1}^{w_{2}^{*}\left(f_{1}\right)}$ never cross each other (and thus only touch each other).

This result follows from Kamihigashi and Furusawa (2010, Proposition 5.2). Figure 6 illustrates an effectively efficient regular IRE. Effective efficiency has an important dynamic implication, as we will see in the next section.

\section{Dynamics of Trade Liberalization}

With the general results established in the previous section in hand, we now focus on the economic implications of the model. For this purpose, we assume that $m_{i}\left(\tau_{i}\right)$ and $x_{i}\left(\tau_{j}\right)$ are 


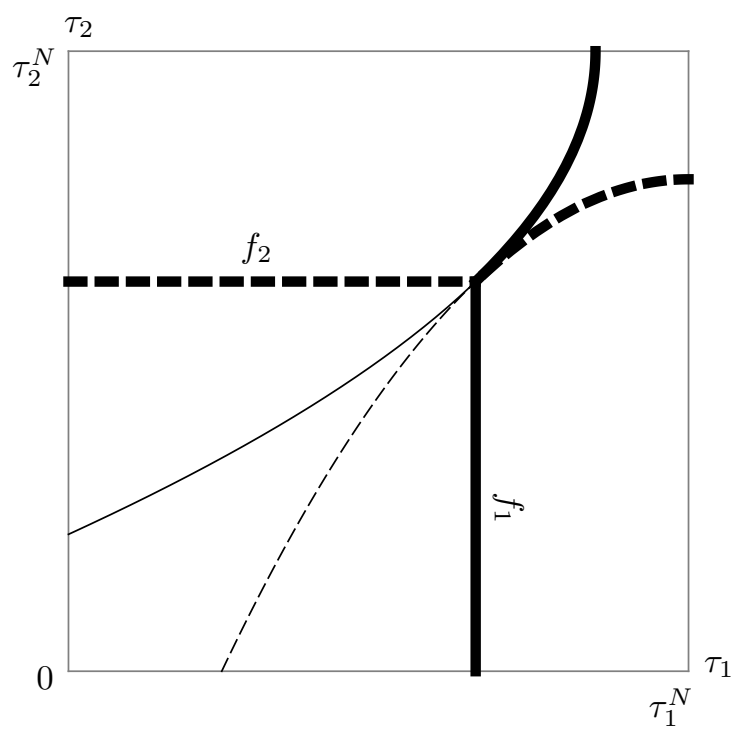

Figure 6: Effectively efficient IRE

differentiable and that $m_{i}^{\prime}\left(\tau_{i}\right)>0$ for all $\tau_{i} \in\left[0, \tau_{i}^{N}\right)$ and $x_{i}^{\prime}\left(\tau_{j}\right)<0$ for all $\tau_{j} \in\left[0, \tau_{j}^{N}\right]$. Since $m_{i}\left(\tau_{i}\right)$ has a single peak at $\tau_{i}=\tau_{i}^{N}$, we have

$$
m_{i}^{\prime}\left(\tau_{i}^{N}\right)=0 \quad \text { for } i=1,2
$$

Since a tariff on country $i$ 's imports creates market distortions, $m_{i}\left(\tau_{i}\right)+x_{j}\left(\tau_{i}\right)$ is maximized at $\tau_{i}=0$ :

$$
m_{i}^{\prime}(0)+x_{j}^{\prime}(0)=0
$$

This is an implication of the well-known result that free trade $\left(\tau_{1}, \tau_{2}\right)=(0,0)$ is Pareto efficient.

The slope of the $\omega_{i}$-level curve of $w_{i}$, or the graph of $g_{j}^{\omega_{i}}$, is calculated from (3.1) to be

$$
\left(g_{j}^{\omega_{i}}\right)^{\prime}\left(\tau_{i}\right)=-\frac{m_{i}^{\prime}\left(\tau_{i}\right)}{\delta_{i} x_{i}^{\prime}\left(g_{j}^{\omega_{i}}\left(\tau_{i}\right)\right)} .
$$

It follows from our assumptions on $m_{i}^{\prime}\left(\tau_{i}\right)$ and $x_{i}^{\prime}\left(\tau_{j}\right)$ that

$$
\left(g_{j}^{\omega_{i}}\right)^{\prime}\left(\tau_{i}\right) \begin{cases}>0 & \text { if } \tau_{i} \in\left[0, \tau_{i}^{N}\right) \\ =0 & \text { if } \tau_{i}=\tau_{i}^{N}\end{cases}
$$

To simplify the exposition, we assume that $g_{j}^{\omega_{i}}$ is strictly concave in $\tau_{i}$ for all relevant 


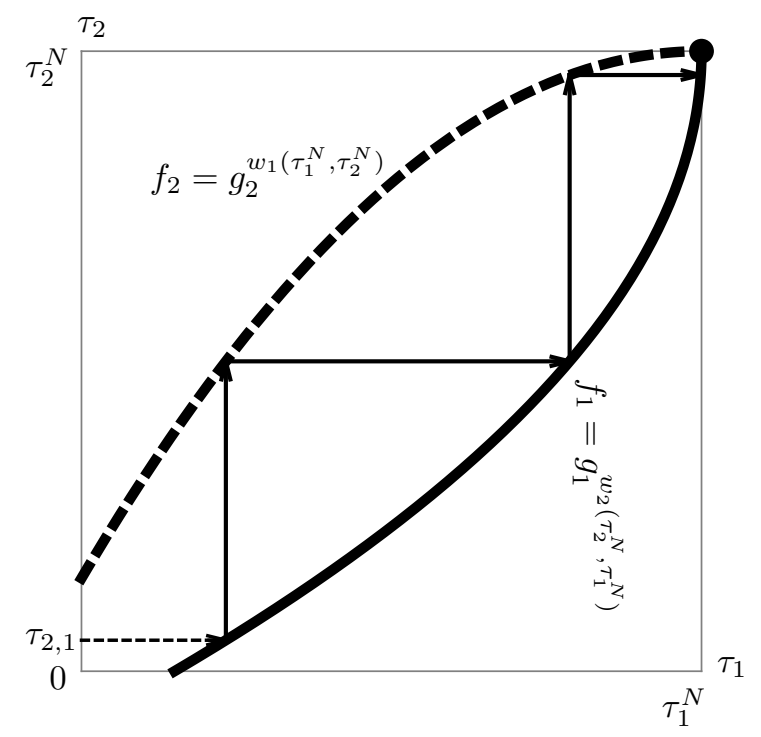

Figure 7: Static Nash steady state

values of $\omega_{i}$, i.e., for all $\omega_{i} \in\left[w_{i}\left(\tau_{i}^{N}, \tau_{j}^{N}\right), w_{i}\left(\tau_{i}^{N}, 0\right)\right.$ ). (See Appendix A for a parametric example that satisfies this assumption.)

Furthermore, we assume for the rest of the paper that

$$
w_{i}\left(\tau_{i}^{N}, \tau_{j}^{N}\right)<w_{i}(0,0) \text { for } i=1,2
$$

so that country $i$ 's level curve extending from $\left(\tau_{i}^{N}, \tau_{j}^{N}\right)$ is located above that extending from the origin (see Figure 7). This assumption is satisfied if the countries are not very asymmetric and have rather high discount factors. Note that since (4.4) can be written as $m_{i}\left(\tau_{i}^{N}\right)-m_{i}(0)<\delta_{i}\left(x_{i}(0)-x_{i}\left(\tau_{j}^{N}\right)\right)$, it is never satisfied if $\delta_{i}$ is close to zero. If both $\delta_{1}$ and $\delta_{2}$ are close to one, on the other hand, the inequality in (4.4) must be satisfied at least for either $i=1$ or $i=2$. This is because $m_{i}\left(\tau_{i}\right)+x_{j}\left(\tau_{i}\right)$ is maximized at $\tau_{i}=0$ (recall (4.2)), so that the sum of the left-hand sides of (4.4) over $i=1,2$ is strictly less than the sum of the right-hand sides when both $\delta_{i}$ are close to 1 . This also indicates that (4.4) holds if both $\delta_{1}$ and $\delta_{2}$ are close to 1 in the special case where the countries are entirely symmetric.

Now, we start by studying the stability properties of some natural steady states. The following proposition, which is illustrated in Figure 7, is a direct consequence of Corollary 
3.1.

Proposition 4.1. There exists a unique regular IRE such that the static Nash equilibrium $\left(\tau_{1}^{N}, \tau_{2}^{N}\right)$ is a steady state. In this IRE, $\left(\tau_{1}^{N}, \tau_{2}^{N}\right)$ is a unique steady state, and is globally stable. More specifically, given any $\tau_{2,1}$, the IRE path converges to $\left(\tau_{1}^{N}, \tau_{2}^{N}\right)$.

In this IRE, even if the initial tariff $\tau_{2,1}$ is close to zero, both countries successively raise their tariffs, and the IRE path converges to the static Nash equilibrium in the long run.

The next proposition, illustrated in Figure 8, considers an IRE that supports free trade as a steady state.

Proposition 4.2. There exists a unique regular IRE such that free trade $(0,0)$ is a steady state. In this IRE, the steady state $(0,0)$ is unstable. More specifically, given any $\tau_{2,1}>0$, the IRE path never converges to $(0,0)$.

This proposition follows from the following result.

Lemma 4.1. In the $\left(\tau_{1}, \tau_{2}\right)$-space, the graph of $g_{2}^{w_{1}(0,0)}$ is strictly steeper than that of $g_{1}^{w_{2}(0,0)}$ at the origin. As $\delta_{1}$ and $\delta_{2}$ both approach one, these slopes converge to each other.

This result is equivalent to saying that $\left(g_{2}^{w_{1}(0,0)}\right)^{\prime}(0)>1 /\left(g_{1}^{w_{2}(0,0)}\right)^{\prime}(0)$ and both sides converge to each other as $\delta_{1}$ and $\delta_{2}$ both approach 1. To see this, note from (4.3) that this inequality is equivalent to

$$
\frac{m_{1}^{\prime}(0)}{x_{2}^{\prime}(0)} \frac{m_{2}^{\prime}(0)}{x_{1}^{\prime}(0)}>\delta_{1} \delta_{2} .
$$

By (4.2), the left-hand side equals 1. Thus the inequality is satisfied, and the right-hand side converges to the left-hand side as both $\delta_{1}$ and $\delta_{2}$ converge to 1 . This establishes the lemma.

Since the graph of $g_{2}^{w_{1}(0,0)}$ is strictly steeper than that of $g_{1}^{w_{2}(0,0)}$ at the origin, the IRE path moves away from the origin if $\tau_{2,1}$ is close to 0 ; indeed, as we can see from Figure 8 , there is no IRE path converging to the origin. 


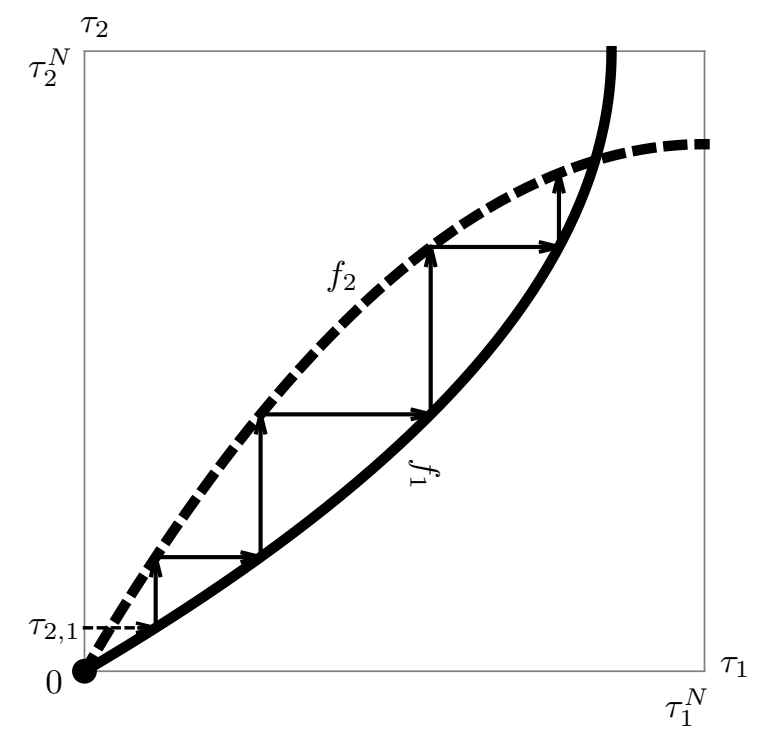

Figure 8: Free-trade steady state

The next result describes IREs with two steady states, including the IRE in Figure 8 as a special case.

Proposition 4.3. There exist regular IREs with two steady states. In these IREs, the higher-tariff steady state $\left(\bar{\tau}_{1}, \bar{\tau}_{2}\right)$ is locally stable, while the lower-tariff steady state $\left(\underline{\tau}_{1}, \underline{\tau}_{2}\right)$ is stable from below and unstable from above. More specifically, if $\tau_{2,1}>\underline{\tau}_{2}$, then the IRE path converges to $\left(\bar{\tau}_{1}, \bar{\tau}_{2}\right)$. If $\tau_{2,1}<\underline{\tau}_{2}$, then the IRE path converges to $\left(\underline{\tau}_{1}, \underline{\tau}_{2}\right)$ in two periods.

Figure 9 illustrates how the IRE path converges to the higher-tariff steady state if $\tau_{2,1}>$ $\underline{\tau}_{2}$. Of particular interest is the case in which $\tau_{2,1}=\tau_{2}^{N}$. This can be considered as a situation in which the initial pair of tariffs is at the static Nash equilibrium, and then country 1 unilaterally lowers its tariff to $\tilde{\tau}_{1,1}<\tau_{1}^{N}$. At this point there is no threat involved in country 1's strategy; indeed, if country 2 does not lower its tariff from $\tau_{2}^{N}$, then country 1 continues to choose $\tilde{\tau}_{1,1}$. It is therefore country 1's "implicit promise" to further lower its tariff, depending on country 2's reaction, that actually gives country 2 an incentive to lower its own tariff. Country 2 for its part makes country 1's promised reaction optimal for country 1 by promising to reciprocate further in case country 1 further lowers its tariff. These 


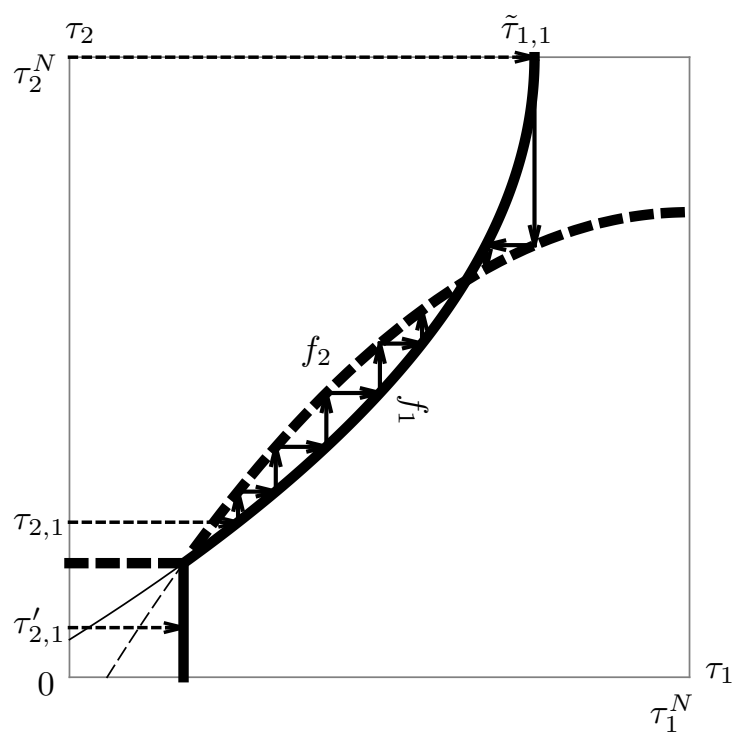

Figure 9: Regular IRE with two steady states

mutually optimal promises result in gradual tariff reduction after country 1's deviation from the static Nash equilibrium, and the IRE path converges to the higher-tariff steady state, which is still lower than the static Nash equilibrium.

It is worth pointing out that this steady state is supported by a minimum "threat." To be specific, suppose that the initial tariffs of both countries are at this steady state. If country 2 makes a small deviation, then country 1 reacts in such a way as to make country 2's effective payoff simply unchanged. In other words, rather than threatening country 2 with a severe punishment, country 1 gives country 2 exactly zero incentive to deviate. Either country thus has nothing to gain as well as nothing to lose by deviating. In contrast with a severe punishment scheme like Nash reversion, this minimum threat is just enough to maintain the steady state and has a built-in mechanism to restore it after a small deviation.

Let us now turn to the lower-tariff steady state, which also has an interesting property. Suppose that the initial pair of tariffs is at this steady state. If either country raises its tariff, then it triggers a tariff war: both countries' tariffs keep rising and converge to the higher-tariff steady state, as depicted in Figure 9. However, if either country lowers its tariff 
rate, the other country does not react at all, for each country $i$ 's reaction function is flat (taking the same level $\underline{\tau}_{i}$ ) for any $\tau_{j} \in\left[0, \underline{\tau}_{j}\right]$. This "kinked" feature is not necessarily an artifact of the specific IRE studied here. In fact, Lemma 3.6 implies that in any IRE, neither country sets a tariff lower than its tariff at the lower-tariff steady state. Therefore, at the lower-tariff steady state, a decrease in either country's tariff is never matched by a decrease in the other country's tariff. At this steady state, by lowering its tariff rate, each country only rewards the other country while incurring a loss.

Under our assumption that the level curves are strictly concave, Lemma 3.7 implies that an IRE with two steady states is not effectively efficient, i.e., it is Pareto dominated by another IRE in terms of effective payoffs. As discussed above, the lower-tariff steady state of such an IRE is unstable from above; in other words, it is difficult to maintain cooperation to keep the tariffs as low as possible in a regular IRE that is not effectively efficient. The following result shows that an effectively efficient regular IRE always yields stable cooperation.

Proposition 4.4. In any effectively efficient regular IRE, there exists a unique, globally stable steady state $\left(\tau_{1}^{*}, \tau_{2}^{*}\right)$, which satisfies

$$
0<\tau_{i}^{*}<\tau_{i}^{N} \quad \text { for } i=1,2
$$

In particular, if $\tau_{2,1}>\tau_{2}^{*}$, then the IRE path gradually converges to $\left(\tau_{1}^{*}, \tau_{2}^{*}\right)$. If $\tau_{2,1}<\tau_{2}^{*}$, then the IRE path converges to $\left(\tau_{1}^{*}, \tau_{2}^{*}\right)$ in two periods.

To see this result, note first that the existence of a unique steady state follows from Lemma 3.7 and the strict concavity of the level curves. The inequalities in (4.5) follow from Propositions 4.1 and 4.2. The stability properties stated in the proposition should be clear from Figure 10, which illustrates an effectively efficient regular IRE. There is a unique steady state $\left(\tau_{1}^{*}, \tau_{2}^{*}\right)$, which is globally stable. If $\tau_{2,1}>\tau_{2}^{*}$, then the IRE path converges to the steady state, as depicted in Figure 10 with $\tau_{2,1}=\tau_{2}^{N}$. If $\tau_{2,1}<\tau_{2}^{*}$, then the IRE path converges 


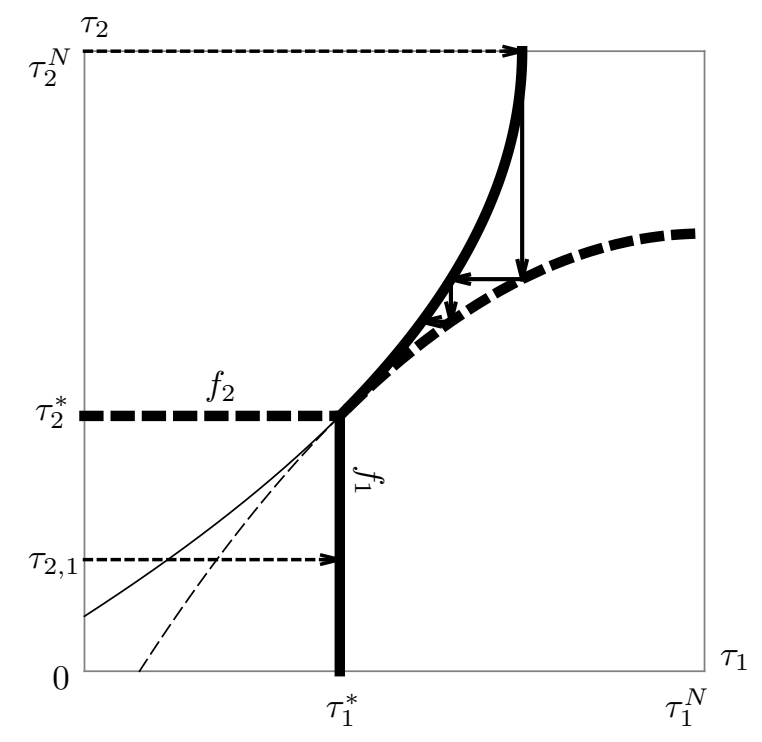

Figure 10: Globally stable steady state

to the steady state in two periods, since country 1 chooses $\tau_{1}^{*}$ whenever $\tau_{2,1}<\tau_{2}^{*}$; i.e., each country faces a kinked reaction curve as at the lower-tariff steady state in Figure 9.

One might wonder why the countries do not lower their tariffs all the way to 0 even in an effectively efficient IRE. A short answer is that the first inequality in (4.5) says that the origin cannot be the steady state of an effectively efficient IRE. To see this intuitively, note that when a country lowers its tariff, it incurs the loss immediately, while it receives the benefit only in the next period, when the other country is expected to reciprocate. Since the future benefit is discounted, free trade involves excessive trade liberalization by both countries so far as Pareto optimality in terms of the effective payoffs is concerned. In the extreme situation where $\delta_{1}$ and $\delta_{2}$ are both 0 , for example, any reciprocal tariff reduction from the static Nash equilibrium reduces each country's effective payoff. Thus, the static Nash equilibrium is Pareto optimal (in terms of the effective payoffs) in this case. As both $\delta_{1}$ and $\delta_{2}$ increase from 0 , the set of Pareto optimal points associated with effective payoffs, which is a downward-sloping curve in the $\left(\tau_{1}, \tau_{2}\right)$-space, shifts down toward the origin and reaches the origin only when $\delta_{1}$ and $\delta_{2}$ both converge to 1 . Since tariffs are gradually lowered only to a Pareto optimal point associated with the effective payoffs, therefore, countries do 
not lower their tariffs all the way to 0 when both $\delta_{1}$ and $\delta_{2}$ are strictly between 0 and 1 .

But it follows from Lemma 4.1 that the steady state $\left(\tau_{1}^{*}, \tau_{2}^{*}\right)$ is close to the origin if $\delta_{1}$ and $\delta_{2}$ are both close to 1 . Starting at the static Nash equilibrium (where $\tau_{2,1}=\tau_{2}^{N}$ ), country 1 unilaterally lowers its tariff in period 1, which triggers reciprocal, gradual tariff reduction. This process will bring the countries almost to free trade if both countries are patient enough. We record this important finding in the following.

Corollary 4.1. In an effectively efficient IRE, a unilateral tariff reduction from the static Nash equilibrium triggers reciprocal, gradual tariff reduction. Although free trade will not be attained in this tariff reduction process, the tariff vector will converge to a steady state that can be arbitrarily close to free trade if both countries are patient enough.

\section{Concluding Remarks}

In this paper, we have analyzed a tariff-setting game between two large countries in which they alternate in setting their individual tariffs. We have focused on the IREs, the subgame perfect equilibria in which each country chooses its tariff according to a stationary function of the other country's tariff. We have fully characterized the IREs of this model and the set of all steady states. We have shown that there are many IREs with two steady states, one with higher tariffs (but still lower than the static Nash tariffs), the other with lower tariffs. The higher-tariff steady state is locally stable, while the lower-tariff steady state is stable from below but unstable from above. We have also shown that in effectively efficient IREs, there exists a unique, globally stable steady state. In most IREs, one country unilaterally reduces its tariff from the static Nash equilibrium, the other country reciprocates in response to the first country's implicit promise to lower its tariff even further, and this process continues forever, converging to a steady state with tariffs lower than at the static Nash equilibrium. We have argued therefore that promises, rather than threats, induce countries to gradually reduce their tariffs. 
A steady state of an IRE has the property that it involves only a minimum threat. Each country makes the other country exactly indifferent between raising its tariff and staying at the steady state. Even if a deviation occurs, each country is willing to lower its tariff again provided that the other country does so. Therefore, the IREs we have studied have a self-enforcing built-in mechanism to restore a stable steady state as well as to initiate a trade liberalization process. This suggests that an explicit agreement may not be necessary to initiate and continue trade liberalization. In a natural environment without any explicit trade agreement, it is possible that a country will unilaterally lower its tariff, which triggers reciprocal, gradual tariff reduction.

\section{Appendix A A Parametric Example}

In this appendix, we derive the surplus functions $m_{i}$ and $x_{i}$ explicitly in a parametric example. We also show that the level curves associated with the effective payoff functions are strictly concave in this example.

Let $p_{i}$ be the domestic price of country $i$ 's import good, which we call good $i$, and $q_{i}$ be the associated trade quantity. We assume that the import demand and export supply functions are identical across the countries, and that country $i$ 's import demand and country j's export supply functions are given by

$$
\begin{aligned}
& q_{i}=1+a-p_{i}, \\
& q_{i}=\left(p_{i}-\tau_{i}\right)-a,
\end{aligned}
$$

where $a>0$ is the autarkic equilibrium price of good $i$ in the exporting country $j$ (and $1+a$ is the autarkic equilibrium price of good $i$ in the importing country $i$ ). In trade equilibrium, $1+a-p_{i}=p_{i}-\tau_{i}-a$, so that

$$
p_{i}=\frac{1+\tau_{i}}{2}+a, \quad q_{i}=\frac{1-\tau_{i}}{2}
$$


Consequently, country $i$ 's import surplus and country $j$ 's export surplus are given by

$$
\begin{aligned}
m\left(\tau_{i}\right) & =\frac{1}{2}\left(1+a-p_{i}\right) q_{i}+\tau_{i} q_{j}=\frac{\left(1-\tau_{i}\right)\left(1+3 \tau_{i}\right)}{8}, \\
x\left(\tau_{i}\right) & =\frac{1}{2}\left(p_{i}-\tau_{i}-a\right) q_{i}=\frac{\left(1-\tau_{i}\right)^{2}}{8}
\end{aligned}
$$

The static Nash equilibrium is $(1 / 3,1 / 3)$.

We assume that the discount factors are common across the countries; we let $\delta$ denote this common discount factor. In what follows we show that the $\omega_{i}$-level curve of country $i$ 's effective payoff is strictly concave for any $\omega_{i} \in\left[w_{i}\left(\tau_{i}^{N}, \tau_{j}^{N}\right), w_{i}\left(\tau_{i}^{N}, 0\right)\right)$. In this example, we have

$$
\begin{gathered}
w_{i}\left(\tau_{i}^{N}, \tau_{j}^{N}\right)=m(1 / 3)+\delta x(1 / 3)=(1 / 6)+(\delta / 18), \\
w_{i}\left(\tau_{i}^{N}, 0\right)=m(1 / 3)+\delta x(0)=(1 / 6)+(\delta / 8) .
\end{gathered}
$$

Recall that the $\omega_{i}$-level curve of country $i$ 's effective payoff is given by the function $g_{j}^{\omega_{i}}\left(\tau_{i}\right)$, which satisfies

$$
\frac{\left(1-\tau_{i}\right)\left(1+3 \tau_{i}\right)}{8}+\frac{\delta\left(1-g_{j}^{\omega_{i}}\left(\tau_{i}\right)\right)^{2}}{8}=\omega_{i} .
$$

Differentiating $\left(g_{j}^{\omega_{i}}\right)^{\prime}\left(\tau_{i}\right)$ given in $(4.3)$ we have

$$
\left(g_{j}^{\omega_{i}}\right)^{\prime \prime}\left(\tau_{i}\right)=-\frac{\delta m^{\prime \prime}\left(\tau_{i}\right) x^{\prime}\left(g_{j}^{\omega_{i}}\left(\tau_{i}\right)\right)^{2}+m^{\prime}\left(\tau_{i}\right)^{2} x^{\prime \prime}\left(g_{j}^{\omega_{i}}\left(\tau_{i}\right)\right)}{\delta^{2} x^{\prime}\left(g_{j}^{\omega_{i}}\left(\tau_{i}\right)\right)^{3}} .
$$

Since $x^{\prime}\left(g_{j}^{\omega_{i}}\left(\tau_{i}\right)\right)<0$ (provided that $\left.g_{j}^{\omega_{i}}\left(\tau_{i}\right) \leq 1 / 3\right)$, we have $\left(g_{j}^{\omega_{i}}\right)^{\prime \prime}\left(\tau_{i}\right)<0$ if and only if

$$
\begin{aligned}
0 & >\delta m^{\prime \prime}\left(\tau_{i}\right) x^{\prime}\left(g_{j}^{\omega_{i}}\left(\tau_{i}\right)\right)^{2}+m^{\prime}\left(\tau_{i}\right)^{2} x^{\prime \prime}\left(g_{j}^{\omega_{i}}\left(\tau_{i}\right)\right) \\
& =\frac{-3 \delta\left(1-g_{j}^{\omega_{i}}\left(\tau_{i}\right)\right)^{2}+\left(1-3 \tau_{i}\right)^{2}}{64}
\end{aligned}
$$

The above inequality is equivalent to

$$
3 \delta\left(1-g_{j}^{\omega_{i}}\left(\tau_{i}\right)\right)^{2}>\left(1-3 \tau_{i}\right)^{2}
$$

Solving (A.1) for $\delta\left(1-g_{j}^{\omega_{i}}\left(\tau_{i}\right)\right)^{2}$ and substituting the resulting expression into (A.2), we find that (A.2) reduces to $\omega_{i}>1 / 6$. This condition is satisfied for any $\delta \in(0,1)$ since $\omega_{i} \in[(1 / 6)+(\delta / 18),(1 / 6)+(\delta / 8))$, so we conclude that all the relevant level curves are strictly concave in this example. 


\section{Appendix B Characterization of Steady States}

In this appendix, we characterize the set of all steady states supported by IREs and divide the set of steady states supported by regular IREs according to their stability properties in the framework of Section 4, although Proposition B.1 and Proposition B.2 are valid even in the less restrictive framework studied in Section 3.

Proposition B.1. There exists an IRE such that $\left(\tau_{1}, \tau_{2}\right) \in\left[0, \tau_{1}^{N}\right] \times\left[0, \tau_{2}^{N}\right]$ is a steady state if and only if

$$
\tau_{i} \leq g_{i}^{w_{j}\left(\tau_{j}^{N}, \tau_{i}^{N}\right)}\left(\tau_{j}\right) \quad \text { for } i=1,2
$$

Proof. If: Let $\left(\tau_{1}, \tau_{2}\right)$ satisfy (B.1). Let $\omega_{1}=w_{1}\left(\tau_{1}, \tau_{2}\right)$ and $\omega_{2}=w_{2}\left(\tau_{1}, \tau_{2}\right)$. Then $g_{1}^{\omega_{2}}$ and $g_{2}^{\omega_{1}}$ satisfy both conditions (i) and (ii) in Lemma 3.5. Define $\left(f_{1}, f_{2}\right)$ by (3.5). Then $\left(f_{1}, f_{2}\right)$ is an IRE by Lemma 3.5. Since $\left(\tau_{1}, \tau_{2}\right) \geq\left(\underline{\tau}_{1}^{\omega_{1}, \omega_{2}}, \underline{\tau}_{2}^{\omega_{2}, \omega_{1}}\right)$, we have $f_{1}\left(\tau_{2}\right)=g_{1}^{\omega_{2}}\left(\tau_{2}\right)$ and $f_{2}\left(\tau_{1}\right)=g_{2}^{\omega_{1}}\left(\tau_{1}\right)$. This together with condition (i) in Lemma 3.5 shows that $\left(\tau_{1}, \tau_{2}\right)$ is a steady state.

Only if: Let $\left(f_{1}, f_{2}\right)$ be an IRE such that $\left(\tau_{1}, \tau_{2}\right)$ is a steady state. Then by Corollary 3.1 , we have $\tau_{1}=g_{1}^{w_{2}^{*}\left(f_{1}\right)}\left(\tau_{2}\right)$ and $\tau_{2}=g_{2}^{w_{1}^{*}\left(f_{2}\right)}\left(\tau_{1}\right)$. Since $w_{1}^{*}\left(f_{2}\right) \geq w_{1}\left(\tau_{1}^{N}, \tau_{2}^{N}\right)$ and $w_{2}^{*}\left(f_{1}\right) \geq$ $w_{2}\left(\tau_{2}^{N}, \tau_{1}^{N}\right)$ by Lemma 3.3 , we have $\tau_{1}=g_{1}^{w_{2}^{*}\left(f_{1}\right)}\left(\tau_{2}\right) \leq g_{1}^{w_{2}\left(\tau_{2}^{N}, \tau_{1}^{N}\right)}\left(\tau_{2}\right)$ and likewise $\tau_{2} \leq$ $g_{2}^{w_{1}\left(\tau_{1}^{N}, \tau_{2}^{N}\right)}\left(\tau_{1}\right)$. Hence we obtain (B.1).

Q.E.D.

Note that the set of $\left(\tau_{1}, \tau_{2}\right)$ satisfying (B.1) is the area bounded by the level curves extending from $\left(\tau_{1}^{N}, \tau_{2}^{N}\right)$; see Figure 3 .

Recall from Lemma 3.4 that any IRE path stays on the associated pair of level curves except for the initial period. Since both level curves are monotone, any IRE path is also monotone after the initial period and thus converges to a steady state. We state this observation as a proposition.

Proposition B.2. Any IRE path converges to a steady state. 
As we have seen in Section 4, each steady state of a regular IRE can be stable from below and unstable from above, locally stable, or globally stable. We can thus divide the set of steady states according to these stability properties.

Figure 11 divides the set of steady states supported by regular IREs into three regions and one curve. The black region (excluding the entire kinked lower left boundary) and the thick black curve comprise the set of globally stable steady states. The kinked lower left boundary of the black region is the locus of the higher intersection of a pair of level curves extending from a common point on the $\tau_{1}$ or $\tau_{2}$ axis. Therefore, a pair of level curves having an intersection in the black region has no other intersection in $\left[0, \tau_{1}^{N}\right] \times\left[0, \tau_{2}^{N}\right]$; thus a point in this region is a globally stable steady state, as Figure 7 shows. The thick black curve is the locus of points of tangency between a pair of level curves; these points are globally stable steady states by Proposition 4.4. The dark gray region is the set of locally stable steady states. A point in this region is above the thick black curve and surrounded by a pair of level curves extending from a common point on the $\tau_{1}$ or $\tau_{2}$ axis. Hence it is the higher-tariff steady state of a regular IRE with two steady states and is thus locally stable by Proposition 4.3. The light gray region is the set of steady states stable from below and unstable from above. A point in this region is below the locus of tangency and is also surrounded by a pair of level curves extending from a common point on the $\tau_{1}$ or $\tau_{2}$ axis. Hence it is the lower-tariff steady state of a regular IRE with two steady states and is stable from below and unstable from above by Proposition 4.3. 


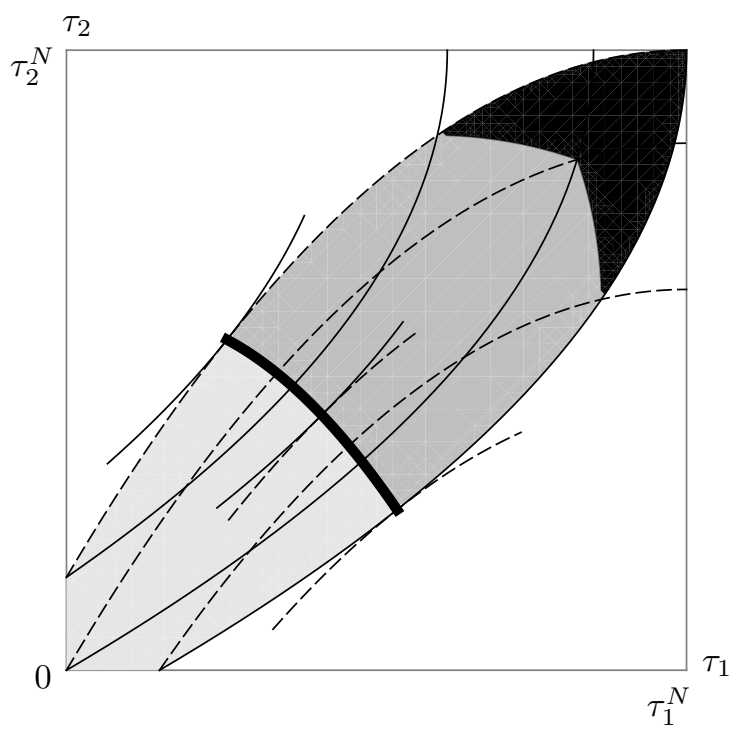

Figure 11: Classification of steady states supported by regular IREs (light gray = stable from below and unstable from above, dark gray = locally stable, black = globally stable)

\section{References}

Bairoch, Paul (1989), "European Trade Policy, 1815-1914," in Peter Mathias and Sidney Pollard (eds.), The Cambridge Economic History of Europe, Vol. 8, Cambridge University Press, Cambridge.

Baldwin, Richard (2010), "Unilateral Tariff Liberalisation," The International Economy, $14,10-43$.

Bhagwati, Jagdish (2002), "Introduction: The Unilateral Freeing of Trade versus Reciprocity," in Jagdish Bhagwati (ed.), Going Alone: The Case for Relaxed Reciprocity in Freeing Trade, MIT Press, Cambridge.

Bond, Eric W. and Jee-Hyeong Park (2002), "Gradualism in Trade Agreements with Asymmetric Countries," Review of Economic Studies, 69, 379-406.

Coates, Daniel E. and Rodney D. Ludema (2001), "A Theory of Trade Policy Leadership," Journal of Development Economies, 65, 1-29.

Conybeare, John A. C. (2002), "Leadership by Example? Britain and the Free Trade Movement of the Nineteenth Century," in Jagdish Bhagwati (ed.), Going Alone: The Case for Relaxed Reciprocity in Freeing Trade, MIT Press, Cambridge. 
Dixit, Avinash (1987), "Strategic Aspects of Trade Policy," in Truman F. Bewley (ed.), Advances in Economic Theory: Fifth World Congress, Cambridge University Press, New York.

Furusawa, Taiji and Edwin L.-C. Lai (1997), "Adjustment Costs and Gradual Trade Liberalization," Journal of International Economics, 49, 333-361.

Johnson, Harry G. (1953-54), "Optimum Tariffs and Retaliation," Review of Economic Studies, 21, 142-153.

Kamihigashi, Takashi and Taiji Furusawa (2010), "Global Dynamics in Repeated Games with Additively Separable Payoffs," Review of Economic Dynamics, 13, 899-918.

Kindleberger, Charles, P. (1975), "The Rise of Free Trade in Western Europe, 1820-1875," Journal of Economic History, 35, 20-55.

Krishna, Pravin and Devashish Mitra (2005), "Reciprocated Unilateralism in Trade Policy," Journal of International Economics, 65, 461-487.

Maskin, Eric and Jean Tirole (1988), "A Theory of Dynamic Oligopoly, I: Overview and Quantity Competition with Large Fixed Costs," Econometrica, 56, 549-569.

Maskin, Eric and Jean Tirole (2001), "Markov Perfect Equilibrium I: Observable Actions," Journal of Economic Theory 100, 191-291.

Staiger, Robert W. (1995a), "A Theory of Gradual Trade Liberalization," in Alan V. Deardorff and Robert M. Stern (eds.), New Directions in Trade Theory, University of Michigan Press, Ann Arbor.

Staiger, Robert W. (1995b), "International Rules and Institutions for Trade Policy," in Gene Grossman and Kenneth Rogoff (eds.), Handbook of International Economics, vol. III, North-Holland, Amsterdam. 